\title{
Expanding the global prevalence of spinocerebellar ataxia type 42
}

Neurol Genet 2018;00:e238. doi:10.1212/NXG.0000000000000238

In the Clinical/Scientific Note "Expanding the global prevalence of spinocerebellar ataxia type 42 ” by Ngo et al., the first and fourth authors' names are missing their middle initials, which should read Kathie J. Ngo and Jason A. Chen, respectively. The publisher regrets the omission. There is also a small typo in the Methods section, which should read, “... with estimated minor allele frequencies drawn from HapMap3 project Centre d'Etude du Polymorphisme Humain-Utah population data." The authors regret the error.

\section{Reference}

1. Ngo K, Aker M, Petty LE, et al. Expanding the global prevalence of spinocerebellar ataxia type 42. Neurol Genet 2018;4:e232. 


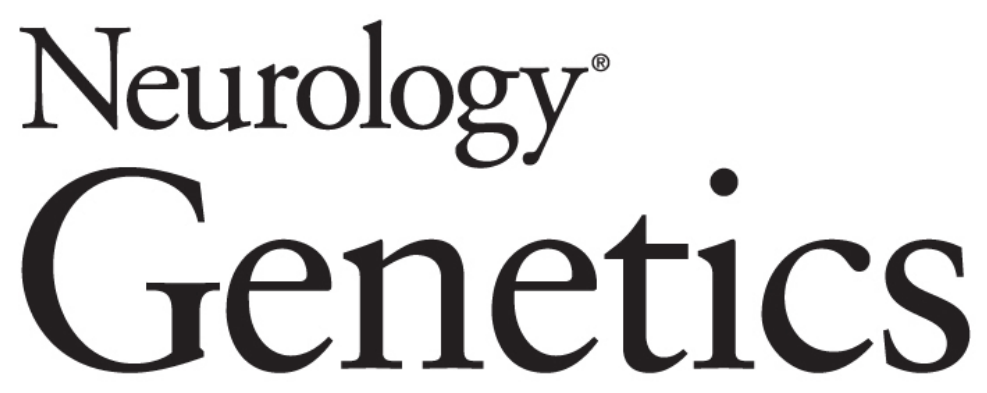

\section{Expanding the global prevalence of spinocerebellar ataxia type 42 Neurol Genet 2018;4; \\ DOI 10.1212/NXG.0000000000000238}

\section{This information is current as of May 18, 2018}

\section{Updated Information \& Services}

References

Subspecialty Collections

Permissions \& Licensing

Reprints including high resolution figures, can be found at: http://ng.neurology.org/content/4/3/e238.full.html

This article cites 1 articles, 1 of which you can access for free at: http://ng.neurology.org/content/4/3/e238.full.html\#\#ref-list-1

This article, along with others on similar topics, appears in the following collection(s):

All Clinical Neurology

http://ng.neurology.org//cgi/collection/all_clinical_neurology All Genetics

http://ng.neurology.org//cgi/collection/all_genetics

All Movement Disorders

http://ng.neurology.org//cgi/collection/all_movement_disorders

Dystonia

http://ng.neurology.org//cgi/collection/dystonia

Information about reproducing this article in parts (figures,tables) or in its entirety can be found online at:

http://ng.neurology.org/misc/about.xhtml\#permissions

Information about ordering reprints can be found online:

http://ng.neurology.org/misc/addir.xhtml\#reprintsus

Neurol Genet is an official journal of the American Academy of Neurology. Published since April 2015, it is an open-access, online-only, continuous publication journal. Copyright $(2018$ American Academy of Neurology. All rights reserved. Online ISSN: 2376-7839.

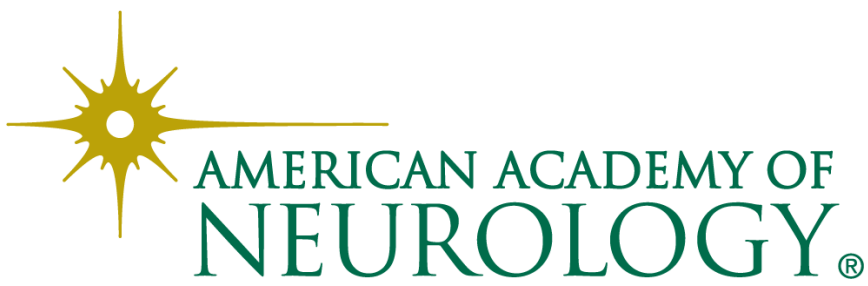

